\title{
Japanese Version of the Parent Health Locus of Control Scales: Validity and Reliability
}

\author{
Akiko Yamada1, Akemi Yamazaki² \\ ${ }^{1}$ Faculty of Nursing, School of Medicine, Nara Medical University, Kashihara, Japan \\ ${ }^{2}$ Division of Health Science, Graduate School of Medicine, Osaka University, Suita, Japan \\ Email: ymakiko@naramed-u.ac.jp
}

How to cite this paper: Yamada, A. and Yamazaki, A. (2019) Japanese Version of the Parent Health Locus of Control Scales: Validity and Reliability. Open Journal of Nursing, 9, 972-987.

https://doi.org/10.4236/ojn.2019.99072

Received: August 13, 2019

Accepted: September 9, 2019

Published: September 12, 2019

Copyright (c) 2019 by author(s) and Scientific Research Publishing Inc. This work is licensed under the Creative Commons Attribution International License (CC BY 4.0).

http://creativecommons.org/licenses/by/4.0/

(c) (i) Open Access

\begin{abstract}
The Parent Health Locus of Control (PHLOC) Scales measure parents' beliefs about the factors that affect their children's health. The aim of our study was to develop a Japanese version of the Parent Health Locus of Control (JPHLOC) Scales and to verify its validity and reliability. The JPHLOC scales consist of six scales: Professional Influence, Parental Influence, Child Influence, Media Influence, Fate Influence, and God, Buddha, and the Spirits Influence. Our questionnaire was administered to 231 principal caregivers from Japan whose children were under 6 years of age. The items, related to the "God, Buddha, and the Spirits Influence" scale, showed a floor effect. The exploratory factor analysis indicated that JPHLOC' six factors functioned similarly to the PHLOC' factors. The Fate Influence and Child Influence factor structures in JPHLOC scales were different from the corresponding factor structures in the original PHLOC scales in the functioning of only one item. There were statistically significant correlations between JPHLOC scales and Japanese version of the Parenting Stress Index-Short Form (PSI-SF), which add evidence to the criterion-related validity of JPHLOC scales. Furthermore, applying the known-groups method, our study showed that there was a significant difference across the JPHLOC scale scores, owning to differences in the children's and caregivers' demographics, which provides an evidence for construct validity. The Cronbach's alpha coefficients for the six scales were estimated between 0.73 and 0.93 . In a test-retest study, the interclass correlation coefficients for the six scales were ranged between 0.80 and 0.90 . The results suggested that the JPHLOC scales have sufficient reliability and validity. The JPHLOC scales are applicable to the caregivers of healthy children. We confirm that the PHLOC scales are also applicable to Japanese caregivers.
\end{abstract}

\section{Keywords}

Children, Health-Related Locus of Control, Caregivers, Nursing, 


\section{Introduction}

When children are in their early developmental stages, it could not be expected of them to act in order to maintain their own health. Therefore, the provision of action, support or supervision by the parents is essential for the maintenance of their children's health [1] [2]. On the other hand, as they grow, children will develop the ability to maintain and promote their own health, and parents would have a significant role in guiding and supporting their children to help them develop their healthcare-related abilities [1] [3] [4]. At the same time, in case where children suffer from any sickness or disability, their parents may perceive it difficult to manage by themselves, and would seek professional medical care. Overall, the maintenance and promotion of children's health are largely influenced by the parents. Thus, in order to help the parents maintain and promote their children's health, the authors reckon that it would be useful to investigate parents' beliefs about who or what determines children's health.

Rotter [5] proposed the construct of Locus of Control based on his social learning theory, stating that events are determined either by one's own behavior (internal locus of control) or by sources that are external to the individual (external locus of control) such as luck, chance, fate or others. Later, in 1978, Wallston et al. [6] developed the Multidimensional Health Locus of Control Scales, which measure health-related locus of control. Furthermore, in order to be able to address children's health, DeVellis et al. [7] developed the Parent Health Locus of Control (PHLOC) Scales, which measure parents' beliefs about who or what influences their children's health. The original PHLOC scales comprise 30 items distributed across six factors: Professional Influence (5 items: e.g., Health professionals keep my child from getting sick), Parental Influence (7 items: e.g., I have the ability to influence my child $s$ well-being), Child Influence (6 items: e.g., My child is in control of his/ her own health), Media Influence (4 items: e.g., What my child sees in TV commercials can affect my child s health), Fate Influence (5 items: e.g., Whether my child avoids injury is just a matter of luck), and Divine Influence (3 items: e.g., God will decide what will happen to my child's health). The questionnaire measures parents' beliefs about the extent to which each factor affects their children's health. Among other languages, the PHLOC scales have been translated from English into Norwegian [8] and Italian [9]. Previous studies showed that there were statistically significant correlations between the six factors of the PHLOC scales and stress in parents of children with congenital heart disease [10]. Furthermore, there was a correlation found between the six factors and anxiety or acute stress symptoms in parents during the 24 hours after their children's surgery [11]. Moreover, previous studies used the PHLOC scales to investigate the extent to which parents believe that they 
themselves, the children, and fate are contributing to prevent accidents in healthy children [12] [13] [14] [15].

However, Japanese version of the PHLOC scales has not been developed yet. Therefore, the aim of our study was to develop the Japanese version of the PHLOC (JPHLOC) Scales and to verify its validity and reliability.

\section{Methods}

\subsection{Development of JPHLOC Scales}

One of the authors translated the PHLOC scales into Japanese with the permission of the author of the original PHLOC scales [7]. Three nursing researchers, who had experience in living abroad, revised independently the Japanese translation. With regard to the items from the Divine Influence scale, we had to introduce some culture-specific changes and to substitute "God" from the original PHLOC scale with "God, Buddha, and the Spirits" in the JPHLOC scale. This revision owes to the fact that most Japanese believe in both Shinto and Buddha, and recently, the practice has developed to respect the concept of spirits. An independent professional translator back-translated the Japanese version three times in total; after each back-translation, we revised the scale to refine it. Three nursing researchers, including the authors, and three graduate nursing students examined the validity of the contents of JPHLOC scales. We discussed evaluating the wording of the JPHLOC scales for appropriateness to the Japanese context. As mentioned above, concerning the items of the God, Buddha, and the Spirits Influence scale, we introduced a mild change in their wording in order to make them more culturally adequate and familiar to Japanese people. Finally, the author of the original PHLOC scales [7] reviewed the translated items and granted us his approval upon the Japanese version of the PHLOC scales.

To confirm the wording of the questions, a pretest was carried out with 13 mothers who were, by the time, engaged in childrearing. As an inclusion criterion for the participants, we decided on inviting for participation only mothers whose children were under 15 years of age. Snowball sampling was used to recruit participants from centers that the authors were acquainted with. The average response time to the questionnaire was 12 minutes. The mean age of the mothers and the children was 39.36 years (standard deviation $[\mathrm{SD}]=4.58$ ) and 4.18 years $(\mathrm{SD}=2.98)$, respectively. The results suggested that further modification of the wording was not needed.

\subsection{Survey Setting}

As an inclusion criterion for the participants, we decided on inviting for participation only principal caregivers whose children were under 6 years of age. Participants were recruited at ten public preschools and one private nursery school, as well as at various health centers, where children were brought for the regular 18-month and 42-month health examinations. All these facilities were located in the same city. In case the recruited caregivers had two or more children who 
were under 6 years old, the questionnaire was directed to the participant's youngest child. Furthermore, in case of participants received the same questionnaire at two or more of the recruitment facilities (i.e., health center, nursery school, or preschool), we asked them to complete it only once.

\subsection{Data Collection}

We asked for permission to conduct this survey from the boards of both the preschool and the health center, and from the head of the private nursery school. We distributed the questionnaire and information sheet to caregivers via the heads or teachers of the preschools and the nursery school. Three weeks after the first distribution, the questionnaire was distributed for the second time at the nursery school for the purpose of retesting the participants. Additionally, we distributed the questionnaire and information sheet directly to the caregivers who took their children to the health center for examination. For the purposes of the retest, some of the caregivers were given a second questionnaire as well and were asked to complete it 3 weeks after the first. All surveys were anonymous, the participants completed the questionnaire by themselves, and sent them back via mail.

\subsection{Instruments}

The questionnaire included questions regarding caregivers' and children's demographic information, and two instruments.

\subsubsection{Caregivers' and Children's Demographic Information Form}

This form consisted of questions about the participant's age and gender, current working status, number of children, children's age, children's gender, children's birth order, whether children attended a hospital regularly.

\subsubsection{The Japanese Version of the Parent Health Locus of Control (JPHLOC) Scales}

The original PHLOC scales consist of six scales (i.e., Professional Influence, Parental Influence, Child Influence, Media Influence, Fate Influence, and Divine Influence) and of 30 items. DeVellis et al. [7] examined the original PHLOC scales' validity and reliability in an American sample and calculated Cronbach's alphas for the six scales between 0.76 and 0.92 .

The JPHLOC scales comprise of 30 items as well. Responses are scored using a 6-point scale ( 1 = strongly disagree; 6 = strongly agree). The JPHLOC scales consist of six scales: Professional Influence, Parental Influence, Child Influence, Media Influence, Fate Influence, and God, Buddha, and the Spirits Influence. The higher the scores for each scale, the stronger the parents believe this factor influences their child's health.

\subsubsection{Japanese Version of the Parenting Stress Index-Short Form} (PSI-SF)

Abidin [16] developed the Parenting Stress Index (PSI), consisting of 101 items, 
in order to investigate the characteristics of parents' stress related to child rearing. The PSI is a screening and diagnostic assessment technique designed to measure the relative magnitude of stress in the parent-child system [16]. Cronbach's alpha estimation for PSI total score was 0.95 [17]. The PSI was adapted in Japanese by Narama et al. [18] and later, based on that adaptation, Araki et al. [19] developed a shortened Japanese version (PSI-SF). The PSI-SF consists of two subscales: Parent Domain subscale (10 items) and Child Domain subscale (9 items) [19]. The Parent Domain subscale measures the parenting burden and the quality of the relationship within the parents' couple. The Child Domain subscale measures the attachment between the parents and children and the sense of children's problems and difficulties. Each item of the PSI-SF scale is scored from 1 to 5 ( 1 = strongly disagree; $5=$ strongly agree $)$, with higher scores indicating stronger parenting stress. The PSI-SF scale is a valid [19] and widely used self-report measure of parenting stress. Cronbach's alpha estimation for PSI-SF total score was 0.82 [19].

We measured PSI-SF in order to verify the criterion-related validity of JPHLOC scales. We predicted that if caregivers perceive weak parental stress, they will believe themselves being able to influence their children's health. While if caregivers perceive stronger parental stress, they will believe that their children's health and safety are to a significant extent not influenced by them, but rather by fate or other factors.

\subsection{Data Analysis}

The statistical analysis was performed using SPSS 23.0J (IBM, Tokyo, Japan). Values of $\mathrm{p}<0.05$ were considered significant. Mean score and standard deviation of the JPHLOC scales were calculated, and floor and ceiling effects of the JPHLOC scales were checked for. Then, we confirmed the normal distribution of the JPHLOC scales using Shapiro-Wilk test.

We evaluated the reliability of the JPHLOC scales using internal consistency and stability coefficients; internal consistency was assessed using Cronbach's alpha, and stability was assessed by the test-retest interclass correlation coefficients (ICC).

We evaluated the structural validity of the JPHLOC scales using exploratory factor analysis. To evaluate the criterion-related validity of the JPHLOC scales, we calculated the Spearman's rank correlation coefficients between JPHLOC scale scores and the PSI-SF. We evaluated construct validity applying the known-groups method [20]. To perform the known-groups method, we divided participants across certain demographic characteristics (e.g., participants' age, children's age, number of children) into two groups according to median value and the distribution of scores for continuous variables. Following the procedure, we divided participants into two groups by their age ( $\leq 35, \geq 36$ years), their children's age ( $\leq 3, \geq 4$ years), and the number of children $(1, \geq 2)$. Furthermore, we also divided participants into two groups based on the children's birth order 
$\left(1^{\text {st }}, \geq 2^{\text {nd }}\right)$ and on whether the children currently attend or have attended a hospital regularly. In order to investigate the difference between the groups on each of the scales, we used the t-test if the scale scores were normally distributed, or Mann-Whitney's U test if scale scores were not normally distributed.

\subsection{Ethics}

We were granted permission to conduct our study from the Research Ethics Committee at Nara Medical University (No. 1452) in 2016 and at Osaka University (No. 16474-7) in 2017.

\section{Results}

\subsection{Demographic Characteristics of the Participants}

We distributed 1198 questionnaires to potential participants from April to November 2017. Two hundred and sixty-five respondents $(22.1 \%)$ returned the questionnaires, and the valid response rate was $19.3 \%$ (231 questionnaires). Table 1 shows the demographic information of the participants. Their mean age is

Table 1. Demographic characteristics of participants $(n=231)$.

\begin{tabular}{|c|c|c|c|c|c|}
\hline & $\mathrm{n}$ & $\%$ & Mean & $\mathrm{SD}$ & Range \\
\hline \multicolumn{6}{|l|}{ Characteristics (caregivers) } \\
\hline Age & 230 & & 36.05 & 5.13 & $23-60$ \\
\hline \multicolumn{6}{|l|}{ Gender } \\
\hline Female (Mother, Grandmother) & 227 & 98.7 & & & \\
\hline Male (Father) & 3 & 1.3 & & & \\
\hline \multicolumn{6}{|l|}{ Current working status } \\
\hline Working & 96 & 41.9 & & & \\
\hline Not working (including, maternity) & 133 & 58.1 & & & \\
\hline Number of children & & & 2.11 & 0.79 & \\
\hline 1 & 48 & 20.8 & & & \\
\hline 2 & 122 & 52.8 & & & \\
\hline 3 & 49 & 21.2 & & & \\
\hline 4 and more & 12 & 5.2 & & & \\
\hline \multicolumn{6}{|l|}{ Characteristics (children) } \\
\hline Children's Age & 230 & & 3.73 & 1.66 & $1-6$ \\
\hline \multicolumn{6}{|l|}{ Gender } \\
\hline Female & 95 & 41.1 & & & \\
\hline Male & 136 & 58.9 & & & \\
\hline Order of birth & & & & & $1-5$ \\
\hline 1 & 107 & 46.3 & & & \\
\hline 2 and more & 124 & 53.7 & & & \\
\hline \multicolumn{6}{|l|}{ Children's regularly attending a hospital } \\
\hline Yes (now, past) & 38 & 16.5 & & & \\
\hline No & 193 & 83.5 & & & \\
\hline
\end{tabular}


36.05 years $(\mathrm{SD}=5.13)$, and the mean age of the children is 3.73 years $(\mathrm{SD}=$ 1.66). The majority of the participants are mothers (98.3\%). Many of the caregivers have two or more children (79.2\%). Only $16.5 \%$ of the children currently attend or have attended regularly a hospital.

\subsection{Score Distribution of JPHLOC Scales}

As shown in Table 2, the means of all items are in the range of 1.64 to 5.15. The only three items related to God, Buddha, and the Spirits Influence scale show a floor effect. No item shows a ceiling effect. The analysis of test normality (Shapiro-Wilk test) revealed that the total scores of the JPHLOC scales had normal distribution $(\mathrm{P}=0.538)$.

Table 2. Means of items, standard deviations, factor loading on 30 items in the Japanese version of Parent Health Locus of Control Scales $(n=231)$.

(a)

\begin{tabular}{|c|c|c|c|}
\hline $\begin{array}{c}\text { Item } \\
\text { no }\end{array}$ & Factors & Mean SD & Factor loading \\
\hline
\end{tabular}

Factor 1. Fate

19 Whether my child can prevent illness is simply up to luck.

$\begin{array}{llllllll}2.10 & 0.88 & 0.82 & -0.09 & 0.02 & -0.02 & -0.02 & -0.02\end{array}$

A great deal of luck influences how healthy my child is.

$\begin{array}{llllllll}2.19 & 1.00 & 0.81 & 0.13 & 0.11 & 0.03 & 0.09 & -0.21\end{array}$

The reason my child stays healthy is mostly because of good luck.

$\begin{array}{llllllll}2.31 & 0.98 & 0.80 & 0.07 & 0.06 & 0.02 & -0.05 & -0.01\end{array}$

30 Whether my child stays healthy or becomes ill is simply a matter of fate.

$\begin{array}{llllllll}2.11 & 0.96 & 0.78 & -0.05 & 0.01 & 0.13 & -0.13 & 0.04\end{array}$

7 Whether my child can prevent injuries is just a matter of luck.

$\begin{array}{llllllll}2.13 & 0.83 & 0.67 & 0.02 & -0.06 & -0.13 & -0.01 & -0.05\end{array}$

5 My child's safety mostly depends on what my child does.

$\begin{array}{llllllll}3.41 & 0.97 & 0.33 & 0.02 & -0.10 & -0.02 & 0.12 & 0.12\end{array}$

Factor 2. Parental

29 I can do many things to keep my child strong and healthy.

$\begin{array}{llllllll}4.56 & 0.80 & 0.04 & 0.87 & 0.04 & -0.12 & -0.05 & 0.08\end{array}$

26 I can do many things to keep my child well. $4.64 \quad 0.82 \quad 0.04 \quad 0.80 \quad-0.06 \quad-0.10 \quad-0.03 \quad 0.13$

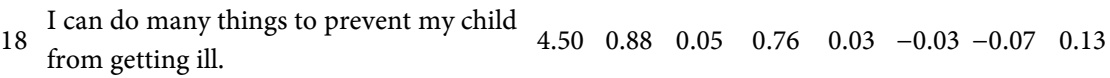

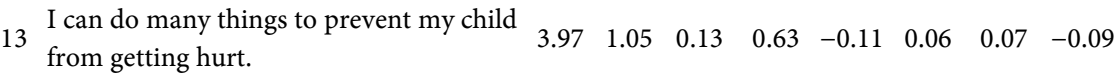

What I do for my child at home is important for my child's health.

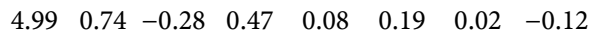

I have the ability to influence my child's health.

$\begin{array}{llllllll}5.15 & 0.75 & -0.12 & 0.46 & -0.03 & 0.13 & 0.16 & -0.13\end{array}$

24 My child's safety depends on me.

$\begin{array}{llllllll}3.81 & 0.94 & 0.02 & 0.41 & -0.02 & 0.02 & 0.11 & -0.16\end{array}$

Factor 3. God, Buddha, and the Spirits

23 God, Buddha, and the spirits are protecting my child's safety.

$\begin{array}{llllllll}1.76 & 0.97 & 0.00 & 0.00 & 0.93 & 0.02 & -0.04 & -0.07\end{array}$ 


\section{Continued}

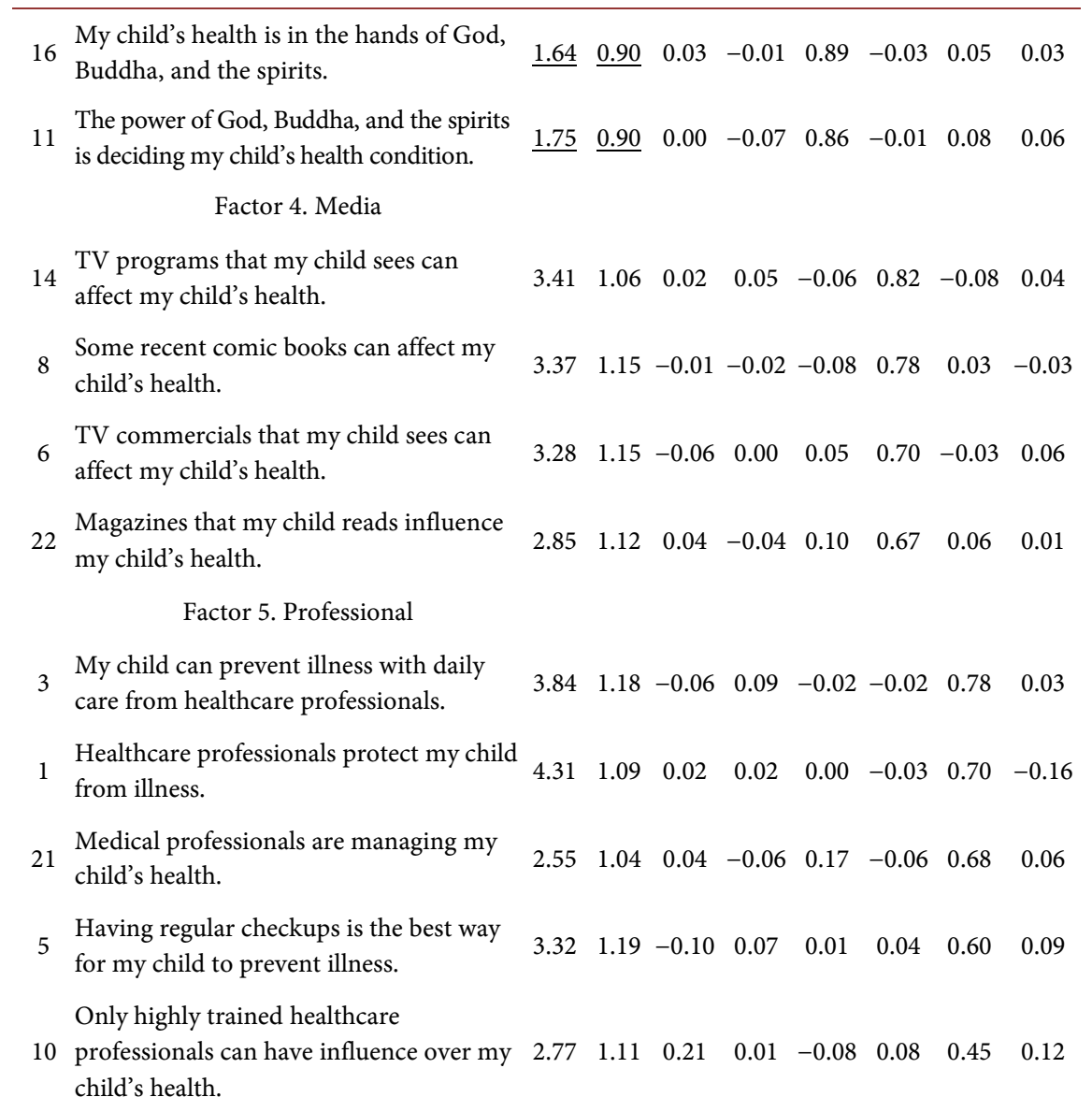
child's health.

\section{Factor 6. Child}

4 My child is managing his/her own health. $2.97 \quad 1.15 \quad-0.13 \quad-0.16 \quad-0.14 \quad-0.06 \quad 0.12 \quad 0.71$

25 My child can do many things to avoid illness.

$\begin{array}{llllllll}3.58 & 1.03 & -0.13 & 0.11 & 0.09 & 0.05 & -0.09 & 0.70\end{array}$

My child can greatly determine his/her own health.

$\begin{array}{llllllll}2.70 & 1.01 & 0.10 & 0.01 & 0.15 & 0.01 & -0.04 & 0.69\end{array}$

17 My child can decide to live a safe and

healthy lifestyle.

$\begin{array}{llllllll}3.89 & 1.13 & 0.02 & 0.09 & 0.04 & 0.09 & -0.01 & 0.50\end{array}$

My child is the one that determines his/her health.

$\begin{array}{llllllll}2.67 & 1.03 & 0.33 & -0.10 & -0.14 & 0.06 & 0.17 & 0.43\end{array}$

(b)

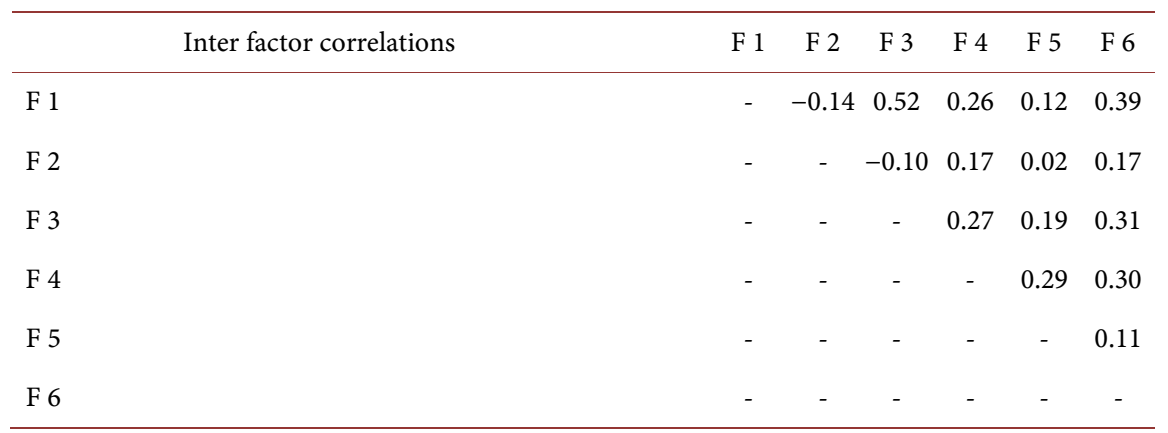

$\mathrm{SD}$, standard deviation Underlined numerals indicate mean $\mathrm{SD}<$ lowest possible score F, Facor. 


\subsection{Structural Validity}

The structural validity of the JPHLOC scales was examined using an exploratory factor analysis and applying the principal factor method. The number of factors was held at six, and Promax rotation was applied. The number of factors was determined in accordance with the original PHLOC scales in order to assess whether the factor solution will be replicated in the JPHLOC scales. The estimation of the Kaiser-Meyer-Olkin measure was 0.82 and Barlett's test of sphericity was significant at $\mathrm{p}=0.000$. Table 2 shows the factor distribution of the 30 items. The factor loadings of the items range between 0.33 and 0.93 . The correlations between the six factors are in the range of -0.14 to 0.52 .

The exploratory factor analysis indicated that JPHLOC's six factors had almost the same distribution of items as the original PHLOC scales, except for only one item (No. 15). Item No. 15 reads "My child's safety mostly depends on what my child does." The original PHLOC scales allot item No. 15 to the Child Influence factor, but the JPHLOC scales allotted item No. 15 to the Fate Influence factor. In order to attempt to solve this issue, we wanted to ensure that the Fate Influence and Child Influence factors as defined by the original PHLOC scales would be applicable to the Japanese version as well. We should verify that both factors would function in a similar way with respect to validity and reliability, whether defined by the JPHLOC solution or by the original PHLOC solution. Therefore, we decided to compose two different scales for each of the factors: one scale would be composed as in the original PHLOC scales and the other as in the JPHLOC scales. To distinguish the two scales for each factor, we marked the JPHLOC scales with " $\dagger$ " (i.e., child ${ }^{\dagger}$, fate $^{\dagger}$ ) as can be seen in Tables 3-5.

\subsection{Criterion-Related Validity}

As shown in Table 3, there was a statistically significant negative correlation

Table 3. Correlation of JPHLOC scales with the other scales $(n=231)$.

\begin{tabular}{cccc}
\hline & \multicolumn{2}{c}{$\begin{array}{c}\text { Japanese Version of the Parenting Stress } \\
\text { Index-Short Forum (PSI-SF) }\end{array}$} \\
\cline { 2 - 4 } JPHLOC scales & Total score & $0.17^{*}$ & $0.23^{* *}$ \\
\cline { 2 - 4 } & $0.21^{* *}$ & $0.16^{*}$ & $0.25^{* *}$ \\
Fate & $0.21^{* *}$ & $-0.19^{* *}$ & $-0.22^{* *}$ \\
Fate & $-0.23^{* *}$ & $0.17^{* *}$ & $0.19^{* *}$ \\
Parental & $0.20^{* *}$ & 0.05 & 0.04 \\
God, Buddha, and the Spirits & 0.03 & $0.15^{*}$ & 0.07 \\
Professional & 0.12 & -0.03 & 0.03 \\
Media & 0.00 & -0.04 & -0.01 \\
Child & -0.03 & Parent & Child \\
Child & & &
\end{tabular}

Spearman's correlation coefficients between factors. ${ }^{*} \mathrm{P}<0.01,{ }^{*} \mathrm{P}<0.05, \dagger$, JPHOC scalesno mark, original PHLOC scales. 
Table 4. Comparison between groups $(n=231)$.

\begin{tabular}{|c|c|c|c|c|c|c|c|c|c|c|c|c|c|c|c|c|c|}
\hline \multirow{2}{*}{\multicolumn{2}{|c|}{ JPHLOC scales }} & \multicolumn{2}{|c|}{ Fate } & \multicolumn{2}{|c|}{ Fate $^{\dagger}$} & \multicolumn{2}{|c|}{ Parental } & \multicolumn{2}{|c|}{$\begin{array}{l}\text { God, Buddha, } \\
\text { and the Spirits }\end{array}$} & \multicolumn{2}{|c|}{ Professional } & \multicolumn{2}{|c|}{ Media } & \multicolumn{2}{|c|}{ Child } & \multicolumn{2}{|c|}{ Child $^{\dagger}$} \\
\hline & & Mean & $\mathrm{SD}$ & Mean & SD & Mean & $\mathrm{SD}$ & Mean & SD & Mean & $\mathrm{SD}$ & Mean & $\mathrm{SD}$ & Mean & SD & Mean & SD \\
\hline \multicolumn{18}{|c|}{ Characteristics (caregivers) } \\
\hline \multicolumn{18}{|c|}{ Age } \\
\hline $23-35$ & $\mathrm{~N}=102$ & 10.5 & 4.2 & 13.9 & 4.6 & 32.4 & 4.3 & 4.7 & 2.4 & 16.0 & 4.1 & 12.6 & 3.8 & 18.9 & 4.3 & 15.5 & 4.0 \\
\hline \multirow[t]{2}{*}{$36-60$} & $\mathrm{~N}=128$ & 11.2 & 3.5 & 14.6 & 3.9 & 31.0 & 4.0 & 5.5 & 2.7 & 17.4 & 4.0 & 13.2 & 3.5 & 19.5 & 4.0 & 16.0 & 3.6 \\
\hline & & n.s b & & n.s b & & ${ }^{*} \mathrm{~b}$ & & n.s b & & ${ }^{*} \mathrm{a}$ & & n.s a & & n.s a & & n.s b & \\
\hline \multicolumn{18}{|c|}{ Number of children } \\
\hline 1 & $\mathrm{~N}=48$ & 10.3 & 4.1 & 13.7 & 4.4 & 32.2 & 4.0 & 5.3 & 3.0 & 18.6 & 4.2 & 12.5 & 3.7 & 18.7 & 5.0 & 15.2 & 4.7 \\
\hline \multirow[t]{2}{*}{2} & $\mathrm{~N}=183$ & 11.0 & 3.7 & 14.4 & 4.2 & 31.5 & 4.2 & 5.1 & 2.5 & 16.3 & 3.9 & 13.0 & 3.7 & 19.3 & 3.9 & 15.9 & 3.5 \\
\hline & & n.s b & & n.s b & & n.s b & & n.s b & & $* * b$ & & n.s a & & n.s a & & n.s a & \\
\hline \multicolumn{18}{|c|}{ Characteristics (children) } \\
\hline \multicolumn{18}{|c|}{ Children's Age } \\
\hline $1-3$ & $\mathrm{~N}=100$ & 10.7 & 3.9 & 14.0 & 4.2 & 32.4 & 4.3 & 4.8 & 2.4 & 17.2 & 4.1 & 12.8 & 3.9 & 18.2 & 4.8 & 15.0 & 4.5 \\
\hline \multirow[t]{2}{*}{$4-6$} & $\mathrm{~N}=130$ & 10.9 & 3.8 & 14.5 & 4.3 & 31.0 & 4.0 & 5.4 & 2.7 & 16.4 & 4.0 & 13.0 & 3.5 & 19.9 & 3.5 & 16.4 & 3.1 \\
\hline & & n.s b & & n.s b & & $* * a$ & & n.s b & & n.s a & & n.s a & & $* * a$ & & ${ }^{* *} \mathrm{~b}$ & \\
\hline \multicolumn{18}{|c|}{ Order of birth } \\
\hline 1 & $\mathrm{~N}=107$ & 10.5 & 4.0 & 13.9 & 4.4 & 32.4 & 4.0 & 5.3 & 2.7 & 16.9 & 4.2 & 12.8 & 3.5 & 19.0 & 4.3 & 15.6 & 3.9 \\
\hline \multirow[t]{2}{*}{2} & $\mathrm{~N}=124$ & 11.2 & 3.7 & 14.6 & 4.1 & 30.9 & 4.2 & 5.1 & 2.5 & 16.6 & 3.9 & 13.0 & 3.8 & 19.4 & 4.1 & 16.0 & 3.7 \\
\hline & & n.s b & & n.sb & & ${ }^{*} \mathrm{~b}$ & & n.s b & & n.s a & & n.s a & & n.s a & & n.s a & \\
\hline \multicolumn{18}{|c|}{ Regularly attending a hospital } \\
\hline $\begin{array}{l}\text { Yes (now, } \\
\text { past) }\end{array}$ & $\mathrm{N}=38$ & 10.7 & 3.9 & 14.3 & 4.3 & 32.0 & 4.2 & 5.3 & 2.8 & 18.2 & 4.0 & 13.4 & 3.3 & 19.9 & 3.8 & 15.7 & 3.8 \\
\hline \multirow[t]{2}{*}{ No } & $\mathrm{N}=193$ & 10.9 & 3.8 & 14.1 & 4.2 & 31.5 & 4.2 & 5.1 & 2.6 & 16.5 & 4.0 & 12.8 & 3.7 & 19.1 & 4.2 & 16.4 & 3.6 \\
\hline & & n.s b & & n.s b & & n.s b & & n.s b & & $* * \mathrm{~b}$ & & n.s b & & n.s b & & n.s b & \\
\hline
\end{tabular}

a, t-testb, Mann-Whitney's U test ${ }^{\star} \mathrm{P}<0.05,{ }^{*} \mathrm{P}<0.01$ n.s, no significant, $\dagger$, JPHOC scalesno mark, original PHLOC scales.

Table 5. Test-retest correlation coefficients of scales $(n=33)$.

\begin{tabular}{cccccc}
\hline \multirow{2}{*}{ JPHLOC scales } & \multicolumn{2}{c}{ test } & \multicolumn{2}{c}{ retest } & \multirow{2}{*}{ ICC } \\
\cline { 2 - 5 } & Mean & SD & Mean & SD & \\
\hline Fate & 11.76 & 4.02 & 10.30 & 3.63 & $0.86^{* *}$ \\
Fate $^{\dagger}$ & 15.21 & 4.56 & 13.85 & 4.09 & $0.87^{* *}$ \\
Parental & 32.09 & 4.16 & 33.24 & 4.62 & $0.83^{* *}$ \\
God, Buddha, and the Spirits & 5.39 & 2.79 & 5.00 & 2.24 & $0.84^{* *}$ \\
Professional & 17.33 & 4.59 & 17.00 & 4.38 & $0.90^{\star *}$ \\
Media & 12.64 & 4.25 & 13.97 & 4.39 & $0.87^{\star *}$ \\
Child & 18.48 & 3.85 & 19.24 & 4.58 & $0.84^{* *}$ \\
Child $^{\dagger}$ & 15.03 & 3.73 & 15.70 & 4.06 & $0.80^{* *}$ \\
\hline
\end{tabular}

ICC, Interclass correlation coefficient ${ }^{* *} \mathrm{P}<0.01, \dagger$, JPHOC scalesno mark, original PHLOC scales. 
between the Parental Influence factor and the PSI-SF (Total score, Parent Distress factor, and Child's Character factor). There was also statistically significant positive correlation between the Fate Influence factor (as defined in the original PHLOC scales, and in the JPHLOC scales) and PSI-SF (Total score, Parent Distress factor, and Child's Character factor).

\subsection{Construct Validity Estimated with the Known-Groups Method}

The results of the known-groups method are shown in Table 4 . When the participants were grouped by age ( $\leq 35, \geq 36$ years) and the groups were compared, the Parental Influence mean scale score was significantly higher for participants aged $\leq 35$. In contrast, the Professional Influence mean scale score was significantly higher for participants aged $\geq 36$ years. As compared with children aged 4 years or more, children aged 3 years or less exhibited higher mean parental scores and lower mean children's scores. When groups were compared based on number of children $(1, \geq 2)$, the Professional Influence mean scale score was significantly higher for the participants with one child. Furthermore, when compared based on children's birth order $\left(1^{\text {st }}, \geq 2^{\text {nd }}\right)$, the Parental Influence mean scale score was significantly higher for participants, whose child was the first in birth order. Finally, when participants were grouped and compared based on whether their children currently attend or have attended regularly a hospital, the Professional Influence mean scale score was significantly higher for the participants whose children have an experience of regularly attending a hospital.

\subsection{Reliability}

The Cronbach's alpha coefficient for JPHLOC scales was estimated at 0.84 for a total of 30 items. The Cronbach's alpha estimations of each scale were as follows: Professional Influence alpha $=0.77$, Parental Influence alpha $=0.82$, Child Influence alpha $=0.73$, Child $^{\dagger}$ Influence alpha $=0.75$, Media Influence alpha $=$ 0.83 , Fate Influence alpha $=0.88$, Fate $^{\dagger}$ Influence alpha $=0.85$, and God, Buddha, and the Spirits Influence alpha $=0.93$. DeVellis suggested a value greater than 0.70 as a respectable bound for Cronbach's alpha when assessing reliability [21]. A test-retest analysis of the same 30 items was conducted as well with 33 participants. Table 5 shows the results from the test-retest; the ICCs are in the range of 0.80 to 0.90 .

\section{Discussion}

In our study, JPHLOC scales were developed and verified for reliability and validity in caregivers of healthy children. As a result, sufficiently reliable and valid JPHLOC scales, consisting of 30 items distributed across six scales, were developed.

According to the score distribution of JPHLOC scales, the three items related to the "God, Buddha, and the Spirits" scale showed a floor effect. One possible explanation could be that the history of separation of religion and state has ex- 
erted a great impact on the Japanese. Therefore, many of them do not practice any particular religion, unlike Christians, and consider themselves as non-religious [22]. Few caregivers declared they belonged to specific Shinto or Buddhist sects. Thus, it seems difficult to regard religion as a familiar source for guidance on management of children's health.

Concerning reliability, for the Japanese adaptation of the PHLOC scales we estimated Cronbach's alpha coefficients in the range of 0.73 to 0.93 for all six scales, which are considered satisfactory according to the conventions in statistics for social sciences [21]. For comparison, the Italian version of PHLOC scales, developed by Bonichini et al. [9], estimated Cronbach's alpha coefficients ranging from 0.72 to 0.91 , which values are as high as the coefficients obtained in our study. Therefore, we can conclude that the internal consistency of JPHLOC scales is satisfactory and the inventory is reliable. Moreover, the ICCs for test-retest reliability for all JPHLOC scales were estimated at 0.80 or higher, supporting the stability of JPHLOC scales.

As for structural validity, the items of JPHLOC scales were distributed across the six scales in the same way as in the original PHLOC scales, except for item No. 15 ("My child's safety mostly depends on what my child does"). Item No. 15 had the highest factor loading in the Fate Influence scale, instead of in the Child Influence scale. This appears to be associated with the fact that Japanese mothers have a lower feeling of self-efficacy for child-rearing than American mothers [23]. In general, infants are very curious, always suffer small injuries and accidents, and are unable to manage their own safety. As Japanese caregivers have a low feeling of self-efficacy for child rearing, they presumably would think that the safety of children cannot be guaranteed by either children themselves or their caregivers, but would be determined by fate. Meanwhile, the study on the development of the Italian version of PHLOC scales showed that only item No. 15 had similar factor loadings in the Fate Influence (0.25) and Child Influence (0.30) scales [9]. This may indicate that Japanese and Italian caregivers shared similar attitudes. Based on these results, given that JPHLOC scales and the original PHLOC scales differ in structure, the former appears to have a factor structure consistent with the characteristics of Japanese caregivers.

Considering the criterion-related validity, we found that PSI-SF and the Parental Influence scale of JPHLOC were negatively correlated. A study conducted on parents of children treated for congenital heart disease or acute disease at hospitals in Egypt, showed that parents with higher parenting stress had significantly lower scores on the Parental Influence scale of PHLOC. The study revealed that these parents do not recognize themselves as a factor for determining children's health [10]. Although the conditions of our study differed from those of the Egyptian study, the same results were obtained. Furthermore, PSI-SF and the Fate Influence scale of JPHLOC were positively correlated. In another study on Canadian parents, scores on the Fate Influence scale of PHLOC were higher as children were more frequently involved in accidents, such as burns and collisions [12]. In other words, a high frequency of children being involved in acci- 
dents is a factor for increasing parenting stress of caregivers, which leads them to rely more on fate than on themselves for preserving their children's health. Thus, the positive correlation between PSI-SF and the Fate Influence scale of JPHLOC appears important and adds evidence to the criterion-related validity of JPHLOC scales.

In analysis of construct validity, we applied the known-groups method. Based on our findings that comparison groups differ in their scores across the scales of JPHLOC owing to different demographic characteristics of the participants and their children, we are confident to confirm the construct validity of JPHLOC scales. Additionally, we found that scores on the Professional Influence scale were higher in caregivers aged 36 years and older. Likewise, among mothers living in Japan who were registered as in need of parenting support in a city, significantly more mothers aged 40 years and older reported difficulty in parenting at the 4-month-old health examination, compared to mothers in their twenties [24]. It has been reported that older mothers do not receive adequate parenting support because their parents are too old to help them [25]. Thus, Yoshioka et al. [24] state that older mothers must seek practical advice from medical personnel about building a new life adapted for the needs of their infants. Therefore, we assume that, as caregivers are older, they ask and entrust more frequently medical professionals with the management of their children's health. Another important result is that scores on the Child Influence scale were lower in caregivers of children aged 3 years and younger. DeVellis et al. [7] also reported similar results showing that scores on the Child Influence scale of original PHLOC were lower in caregivers of preschool-age children than in caregivers of school-age children. DeVellis et al. [7] stated that it was reasonable for caregivers of small children to rarely recognize children themselves as an influential factor for their own health.

\section{Study Limitations}

The author of the original PHLOC scales developed the items of his inventory using a sample of parents of preschool and elementary school children [7]. However, our study excluded as participants the caregivers of elementary school children, which might have affected the Fate Influence scale score. It will be necessary to conduct a comparable research on the JPHLOC scales with the participation of caregivers of elementary school children. Furthermore, all the facilities at which we distributed the questionnaire (i.e., health center, preschool, and nursery school) were located in only one city. Thus, the health and healthcare conditions in the city might have influenced the results of the study. Therefore, it would be necessary to be careful when generalizing these findings.

\section{Conclusions}

We developed a Japanese version of the PHLOC scales and verified its validity and reliability using a sample of 231 caregivers, whose children were aged under 
6 years old. The results suggested that the JPHLOC scales had sufficient reliability and validity. The JPHLOC scales appear to facilitate the identification of people who could be recognized as responsible for the management of children's health. Therefore, this scale can be used to support the parents of children with chronic diseases treated at outpatient clinics to transfer the main responsibility for their child's healthcare to the child him/herself as children grow up. Moreover, when children suddenly become ill, the scale can also be used to support the parents to calmly take care of them at home and to determine objectively when it is necessary to bring them to a hospital.

Concerning the comparability of the factor structures of JPHLOC scales and original PHLOC scales and their functioning, the items related to the "God, Buddha, and the Spirits Influence" scale showed a floor effect. Additionally, the Fate Influence and Child Influence factors as defined in JPHLOC consisted of different items in comparison to the same factors as defined in the original PHLOC. Both of these findings seem to reflect the specificities of the Japanese caregivers' parenting view.

Furthermore, regarding the Fate Influence and Child Influence factors, their reliability and validity coefficients proved to be very similar between the JPHLOC scales and the original PHLOC scales. Thus, we confirm that the PHLOC scales are applicable to Japanese caregivers.

\section{Acknowledgements}

We thank the caregivers who participated in this research.

\section{Conflicts of Interest}

The authors declare no conflicts of interest regarding the publication of this paper.

\section{References}

[1] Orem, D.E., Taylor, S.G. and Renpenning, K.M. (2001) Nursing: Concepts of Practice. Mosby, St. Louis, MO.

[2] Beets, M.W., Cardinal, B.J. and Alderman, B.L. (2010) Parental Social Support and the Physical Activity-Related Behaviors of Youth: A Review. Health Education and Behavior, 37, 621-644. https://doi.org/10.1177/1090198110363884

[3] Pyper, E., Harrington, D. and Manson, H. (2016) The Impact of Different Types of Parental Support Behaviours on Child Physical Activity, Healthy Eating, and Screen Time: A Cross-Sectional Study. BMC Public Health, 16, 568. https://doi.org/10.1186/s12889-016-3245-0

[4] Adamo, K.B. and Brett, K.E. (2014) Parental Perceptions and Childhood Dietary Quality. Maternal and Child Health Journal, 18, 978-995.

https://doi.org/10.1007/s10995-013-1326-6

[5] Rotter, J.B. (1966) Generalized Expectancies for Internal Versus External Control of Reinforcement. Psychological Monographs: General and Applied, 80, 1-28. https://doi.org/10.1037/h0092976

[6] Wallston, K.A., Wallston, B.S. and DeVellis, R. (1978) Development of the Multi- 
dimensional Health Locus of Control (MHLC) Scales. Health Education Monographs, 6, 160-170. https://doi.org/10.1177/109019817800600107

[7] DeVellis, R.F., DeVellis, B.M., Blanchard, L.W., Klotz, M.L., Luchok, K. and Voyce, C. (1993) Development and Validation of the Parent Health Locus of Control Scales. Health Education Quarterly, 20, 211-225. https://doi.org/10.1177/109019819302000213

[8] Kraft, P. and Loeb, M. (1996) On the Replicability and Correlates of the Parent Health Locus of Control Scales. Health Education Research, 11, 433-441. https://doi.org/10.1093/her/11.4.433

[9] Bonichini, S., Axia, G. and Bornstein, M.H. (2009) Validation of the Parent Health Locus of Control Scales in an Italian Sample. Italian Journal of Pediatrics, 35, Article No. 13. https://doi.org/10.1186/1824-7288-35-13

[10] Ezzat, S., Saeedi, O., Saleh, D.A., Hamzeh, H., Hamid, M.A., Crowell, N., Boostrom, C., Loffredo, C.A. and Jillson, I.A. (2016) Parental Perceptions of Congenital Cardiovascular Malformations in Their Children. Cardiology in the Young, 26, 1158-1167. https://doi.org/10.1017/S104795111500253X

[11] Scrimin, S., Haynes, M., Altoè, G., Bornstein, M.H. and Axia, G. (2009) Anxiety and Stress in Mothers and Fathers in the $24 \mathrm{~h}$ after Their Child's Surgery. Child: Care, Health and Development, 35, 227-233. https://doi.org/10.1111/j.1365-2214.2008.00920.x

[12] Morrongiello, B.A. and House, K. (2004) Measuring Parent Attributes and Supervision Behaviors Relevant to Child Injury Risk: Examining the Usefulness of Questionnaire Measures. Injury Prevention, 10, 114-118. https://doi.org/10.1136/ip.2003.003459

[13] Morrongiello, B.A., Corbett, M., McCourt, M. and Johnston, N. (2006) Understanding Unintentional Injury Risk in Young Children II. The Contribution of Caregiver Supervision, Child Attributes, and Parent Attributes. Journal of Pediatric Psychology, 31, 540-551. https://doi.org/10.1093/jpepsy/jsj073

[14] Barton, B.K. and Huston, J. (2012) The Roles of Child, Parent and Environmental Factors in Pedestrian Supervision. International Journal of Injury Control and Safety Promotion, 19, 153-162. https://doi.org/10.1080/17457300.2011.635210

[15] Schnitzer, P.G., Dowd, M.D., Kruse, R.L. and Morrongiello, B.A. (2015) Supervision and Risk of Unintentional Injury in Young Children. Injury Prevention, 21, e63-e70. https://doi.org/10.1136/injuryprev-2013-041128

[16] Abidin, R.R. (1983) Parenting Stress Index-Manual. Pediatric Psychology Press, Charlottesville, VA.

[17] Abidin, R.R. (1995) Parenting Stress Index. 3rd Edition, Psychological Assessment Resources, FL.

[18] Narama, M., Kanematsu, Y., Araki, A., Maru, M., Nakamura, N., Takeda, J., Shirahata, N. and Kudo, Y. (1999) Validity and Reliability of the Japanese Version of the Parenting Stress Index. The Journal of Child Health, 58, 610-616.

[19] Araki, A., Kanematsu, Y., Yokosawa, S. Arayashiki, A., Aizumi, I. and Hujihima, K. (2005) A Study for Developing Parenting Stress-Short Form Scale. The Journal of Child Health, 64, 408-416.

[20] Polit, D.F. and Beck, C.T. (2004) Nursing Research: Principles and Method. Lippincott Williams \& Wilkins, Philadelphia, PA.

[21] DeVellis, R.F. (2017) Scale Development: Theory and Applications. SAGE Publications, Los Angeles, CA. 
[22] Tanaka, K. (2010) Limitations for Measuring Religion in a Different Cultural Context-The Case of Japan. The Social Science Journal, 47, 845-852. https://doi.org/10.1016/j.soscij.2010.07.010

[23] Suzuki, S., Holloway, S.D., Yamamoto, Y. and Mindnich, J.D. (2009) Parenting Self-Efficacy and Social Support in Japan and the United States. Journal of Family Issues, 30, 1505-1526. https://doi.org/10.1177/0192513X09336830

[24] Yoshioka-Maeda, K. and Kuroda, M. (2017) Characteristics and Related Factors of Japanese Mothers Who Have Faced Difficulties with Childrearing. Public Health Nursing, 34, 422-429. https://doi.org/10.1111/phn.12328

[25] Yang, Y.O., Peden-McAlpine, C. and Chen, C.H. (2007) A Qualitative Study of the Experiences of Taiwanese Women Having Their First Baby after the Age of 35 Years. Midwifery, 23, 343-349. https://doi.org/10.1016/j.midw.2006.03.009 